\title{
Yoga Practices for Prevention and Management of Lifestyle Disorders
}

\section{Ananda Balayogi Bhavanani *}

Stress is inevitable in the modern world because of the imbalance between the demands of one's environment and one's capabilities. In fact, it is the distress, which causes the problem and can be defined as every physical and mental tension that we experience as unpleasant. The environment today is more demanding. From childhood onwards, the development of capacities and capabilities of the individual is not able to keep pace with the increase of demands on them. This gap in most cases goes on widening. The huge crowds at Temples, churches and mosques in some way or the other are related to this imbalance. Everyone seems to be going there in order to beg or bribe the almighty to perform the balancing act.

When we talk of stress we must also remember that some amount of stress is necessary in order to bring out the best in us. However it is vital to learn how to manage stress and keep it under our control. It is important to also remember the words of Epictetus in 60 A.D. who said, "Men are not disturbed by things, but the views, they take of them". As Swamiji Gitananda Giri Guru Maharaj jocularly used to say' "You don't have problems-you are the problem!" A positive frame of mind will help us to be cheerful and unstressed. Maharishi Patanjali's advise in this regard to cultivate Pratipaksha Bhavanam (The Opposite View) is vital to achieve balance of the emotions and mind. It is also worth trying to follow his advice of Maitri-Sukha (Friendliness towards the happy), Karuna-Dukha (Compassion towards the suffering), Mudhita-Punya (Cheerfulness towards the virtuous) and Upekshanam-Apunya (Indifference towards the wicked).

The most common causes of stress are the Shat Ripus or the six enemies of the spirit. These are Kama (Uncontrolled passion), Krodha (Senseless Anger), Lobha (Greed), Moha (Blind infatuation), Mada (Massive Ego) and Matsarya (Malice / envy). Corruption of character, conduct, thought and interpersonal dealing is another cause of stress.

An environment where sadistic pleasure gives satisfaction, where ethics have little or scant regard, where self-interest is more important and where under cutting and backbiting are a common feature, will surely lead to the development of extreme stress. It is important to realise these facts and be aware of them in our life. Unless we develop awareness and consciousness of what we think, feel and do, there cannot be a lasting solution to stress. We must strive to become persons of "Equal mindedness in all situations" that is described as Stitha Prajna or Samabhava in the Srimad Bhagavad Gita.

Though stress probably cannot be avoided, it can, however, be managed. The following actions may help reduce/ eliminate the stress.

1. Awareness: It is important that we first become aware of the stress and then try to let it go. Sharing your tension with a friend and/or a family member may solve the problem to a great extent. You cannot wish away problems by nonacknowledgement of them.

2. Movement: Movement helps in reducing tension. This can mean walking, jumping, making noise, swimming and playing. Stress tends to accumulates in the joints and movement helps to dissipate it. Rotation of the neck and shoulders in many cases helps a lot. Some corporates have even established stress-relieving chambers where employees may shout, screams or hit a hanging pillow to relieve the pent up tension.

3. Yoga techniques: The regular practice of various Yoga techniques and inculcating the Yogic values in daily life will go a long way towards not only reducing the stress levels bit also in giving us that elusive "Peace of Mind". Yogic relaxation practices such as Shavasana and Yoga Nidra help to create a sense of awareness and relaxation in the whole body as well as the mind.

4. Hobby: A hobby can help to relieve tension because it helps us to divert our mind from an unpleasant occurrence. Music, dance, painting, cooking and gardening are effective ways to take our mind to a different "Zone". Playing with your pet can also help relieve tension and many people have "Thera-pets" or pets that help them therapeutically!

5. Breathing: Breathing is one of the easiest ways of relieving stress. Whenever you feel tension rising, take a few

\footnotetext{
* Yogacharya Dr. Ananda Balayogi Bhavanani, MBBS, ADY, DPC, DSM, PGDFH, PGDY, FIAY, MD (Alt.Med)

Deputy Director, CYTER, MGMCRI, SBVU and Chairman ICYER at Ananda Ashram, Pondicherry.

Email: yoga@mgmcri.ac.in and yognat@gmail.com
} 
deep breaths and you will immediately feel the difference.

6. Attitude: It is important to "Let things lie" for sometime when facing problems and many situations resolve on their own. Other situations may appear smaller and less stressful after some time. Development of a detached attitude can also help us to have a better perception of situations and this in turn helps us to face them better.

7. Visualization: Visualization of a pleasant solution to the problems can also help a lot. This is quite different from daydreaming. This is widely adopted by players and athletes for improving their performance. After a stressful encounter, coolly sit in your chair, close your eyes and visualize the episode as an act of an ignorant person and excuse him for the incident.

8. Auto-Suggestion: Another mental technique is Positive self-suggestion. The negative thoughts are to be replaced with positive ones and an attitude of 'I can and I will ' is to be developed.

9. Self effort: Stress is related to the individual's environment and their tolerance capacity. As both of these are different in different people, each individual has to settle for their own method for managing their day-to-day problems. It must be clearly understood that we are responsible for our health and happiness and have a duty to take care of these Divine gifts. Swami Gitananda Giri used to often say, "Health and happiness are your birthright". It is through our own efforts and will power that we can ultimately solve the problem of stress and achieve our birthrights.

Yoga is an integrated way of life in which awareness and consciousness play a great part in guiding our spiritual evolution through life in the social system itself by understanding that "Yoga is the science and art of right-use-ness of body, emotions and mind".

\section{Basic Warming Up Practices}

Jattis are basic movements of the body parts that help to release pent up tensions in those parts. They increase circulation to the part and also the flow of Pranic energy is increased due to the movements. A few of these practices will be described now.

Take up a comfortable standing position such as the Samasthiti Asana. Stand on one leg and shake the other leg. Repeat on the other side and then alternate a few times between right and left. Stand on both legs and start to shake your hands one at a time. Alternate between the right and left a few times and then start to shake both hands at the same time.

Shake your hands and move them up, down, to the left and to the right. Shake your hands all around you in a circular movement. This helps to energize the Pranamaya Kosha, our energy sheath or subtle body. Come back to the standing position.

Open the legs two feet apart and keep the hands on the hip. Move the torso in all four directions clock-wise and anti clock-wise in a grinding action. Then do it in a continuous manner. Bend forward and perform some toe touching with a bouncing action. Bounce to the front, and then move to your left. Move to your right and then come back to the front. Come back to the standing position.

Spread your feet a bit and lift both your arms to the side. Start to twist your torso from side to side a few times. Feel the stretch in your hip region and back. Come back to the standing position and relax with deep breathing for some time.

Sit down with both legs stretched out in front of you. Draw your right knee up to your chest and then kick out with a whooshing sound. Perform the same action on the left side. Continue to alternate legs for some time. Draw up both your knees and do the same action with a whooshing sound as you release the feet. Relax with your feet stretched out in front.

\section{SURYA NAMASKAR}

Rishikesh Surya Namaskar, the Yogic sun salutation is a series of twelve physical postures. These alternating backward and forward bending postures flex and stretch the spinal column through their maximum range giving a profound stretch to the whole body. The basic breathing principle is to inhale during upward and backward bending postures and exhale during forward bending postures.

Stand erect with your feet close together. Perform Namaskar Mudra by joining your palms together in front of your chest.

Breathe in and stretch your arms over your head into the Anjali Mudra and then arch your back. Feel the healthy stretch in your whole body.

Breathe out and bend forward while keeping your arms and back in one line and as straight as possible. Perform the Pada Hasta Asana by bringing your head to your knees while keeping your hands on either side of your feet.

Breathe in and extend your right leg back until it is straight as possible and you are balanced on your toes and hands. Your left leg should be bent with the sole flat on the ground. Lift your head and bend back and open up your chest. This 
is the Ashwa Sanchalana Asana, the equestrian posture.

While breathing out bring your left leg back towards the right and keep the feet just a foot apart with your heels flat to the ground. Simultaneously raise your buttocks and lower your head between your arms, so that your body forms a triangle with the ground. This is the Mehru Asana or mountain posture. While maintaining the posture, take a deep inhalation.

While breathing out drop both knees to the ground and slowly slide the body down at an angle and bring your chest and chin to the ground. Eight parts of your body namely your toes, knees, chest, hands and chin should touch the ground while the buttocks are kept up. You're your breath while performing this Ashtanga Bhumi Sparsha, the eight limbed prostration.

Breathe out and come into Bhujanga Asana, the Cobra posture. Focus your awareness at the base of your spine and feel a healthy stretch in your back and neck.

Exhale and come back to the Mehru Asana, the mountain posture. This strengthens the arms and legs as well as the spinal column. Inhale and bring your right leg forward in-between your hands while keeping your left leg in its original

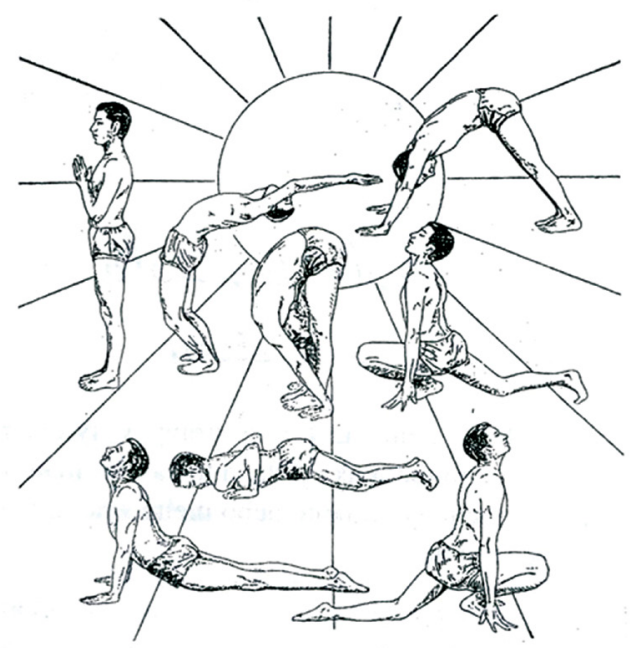

position to perform the Ashwa Sanchalana Asana. Breathe out and bring your left foot forward to come into the Pada Hasta Asana. Breathe in and come up and perform the Anjali Mudra and bend backward. Breathe out and come back to the standing while bringing your hands back to the chest in Namaskar Mudra.

To perform the Rishikesh Surya Namaskar on the opposite side perform the practice again with a slight modification. To complete the other half the same movements are repeated except that the left leg is brought back while performing the Ashwa Sanchalana the first time. The other postures such as Mehru Asana, Ashtanga Bhumi Sparsha and Bhujanga Asana are done in the same manner. When coming back to the Ashwa Sanchalana the left foot is brought forward and then the Pada Hasta is performed by joining right foot to the left before completing the practice with the Anjali Mudra and finally relaxing in the Sama Sthithi with deep breathing.

One full round consists of the 12 poses done twice in sequence. Practice 3 to 9 rounds of the Surya Namaskar daily for maximum benefit. When the exercises are done little quickly the gain is more physical and when they are done slowly with breath awareness the gain is more mental and spiritual.

\section{Yoga Asanas}

\section{TALA KRIYA}

The term, "Tala" refers to a Palmyra tree and you should try to stretch yourself as tall as that tree while performing this practice. Take up a comfortable and stable Samasthiti Asana. Breathe in and lift both arms up over your head until they are parallel to each other. Let the palms of both hands face inward and then go up onto your toes and stretch up as high as possible. Hold the breath and feel the healthy stretch along your whole body from toes to finger tips. Breathe out and relax your arms back to your sides while coming back to the flat foot posture. Repeat the practice two more times at each session for maximum benefit. With practice the posture can be held for a longer time and normal breathing done while holding the posture for 30 to 45 seconds.

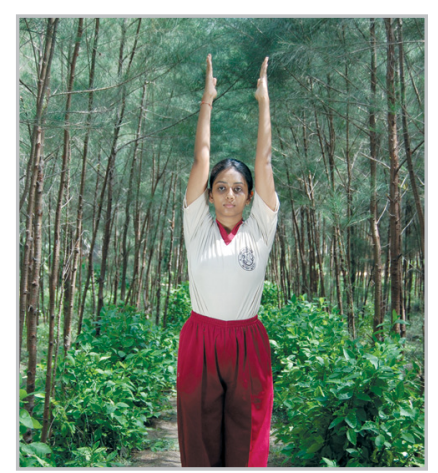

\section{HASTHA KONA KRIYA}

Stand in a steady Samastiti Asana with your arms by your side. Breathe in and lift your right arm over your head. Try to extend the arm over your head towards the left as far as possible without bending it. This gives a good stretch to 


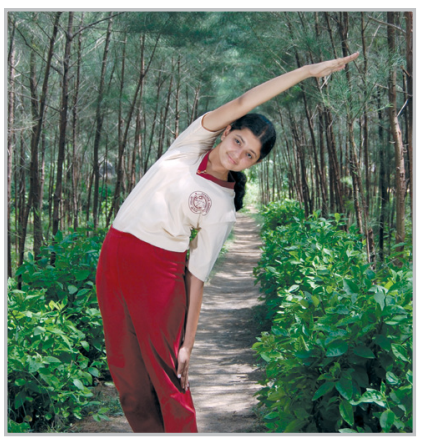

the entire right side of the body. Slowly start to breathe out and lower your arm slowly back to the side. Repeat the practice a few more times.

Make sure that you lift your arm on the in breath and lower it on the out breath. Perform the practice on the opposite side by lifting your left arm over your head while breathing in. Extend it as far towards the right as possible without bending it. Feel the excellent stretch on the entire left side of your body. Lower your arm back to your side while breathing out. Repeat the practice a few more times.

The Hastha Kona Kriya helps to stretch and tone up the musculature of the arms, shoulders and the Para-spinal area in a way not done in day-to-day life. This helps trigger the relaxation response in these tissues that are normally tensed due to disuse, misuse and abuse. A sense of profound relaxation is obtained after the practice of this activity that is also known as the Ardha Kati Chakrasana.

\section{TRIKONA ASANA}

Stand in Samasthiti Asana. Place your feet two to three feet apart facing forwards. Stretch your arms to the sides so that they are pulling the chest in opposite directions. Turn your head and right foot to the right side and slowly bring your right hand down to the right foot and place the palm of the right hand on the ground in front of the right foot. Look up at the middle finger of the left hand. Let the entire torso get a good twist and stretch. Hold the position for 30 seconds while performing deep breathing. Release and come back up to the open arm position and then do the opposite side by placing your left hand down in front of the left foot. Hold the position for 30 seconds while performing deep breathing. When ready come back up to the Samasthiti Asana and relax with a few rounds of deep breathing.

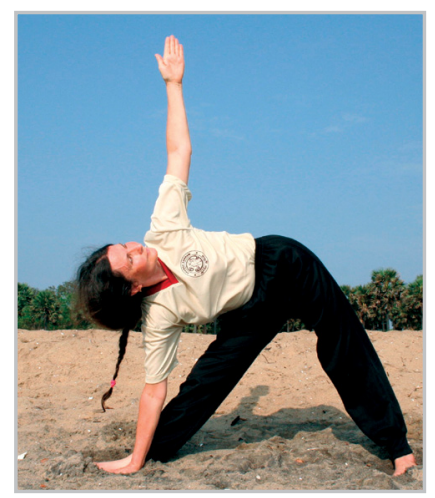

\section{VAKRA ASANA}

Sit erect with your legs stretched out in the Uttana Asana. Bend your right knee and place the right foot by the side of the left knee. Turn to your right and place your right hand on the ground behind you to support your erect position. Bring your left arm round the outer side of the right knee and catch hold of the right big toe. Turn your head and look back over your right shoulder. The erect knee acts as a fulcrum for getting maximum twist of the spine. Keep your torso as straight as possible. Hold the posture for 30 seconds with soft breathing.

Release the posture and come back to the Uttana Asana. This posture gives an excellent massage to the abdominal organs and is very useful for those suffering from diabetes as well as digestive disorders. It is also useful for neck and back problems. Repeat the practice on the opposite side in a similar manner. Hold the posture for 30 seconds with soft breathing. Release the posture and come back to the Uttana Asana and relax with deep breathing for some time.

\section{ARDHA MATSYENDRA ASANA}

Sit erect with both legs stretched out in front and your palms gently pressing on the ground by your sides in Uttana Asana. Fold your right knee and place the heel tight in against the perineum. Place your left foot by the side of your right thigh by crossing it over the knee. Bring your right hand round the outer side of the left knee passing between the chest and the knee and catch hold of the left big toe. Your right shoulder blade rests on the outer side of your left knee.

Take your left hand round your back and try to get a grip on your right thigh. Look back over your left shoulder. The erect knee acts as a fulcrum for getting maximum twist of the spine. Keep your trunk vertical. Hold the posture for 30 seconds with soft breathing. This posture gives an excellent massage to all the abdominal organs and is very useful for those suffering from diabetes as well as digestive disorders.

Release and come back to the Uttana Asana.

Repeat on the opposite side by folding your left knee with the heel tight in against the perineum. Place your right foot by the side of your left thigh by crossing it over the knee. Bring your left hand round the outer side of the right knee passing between the chest and the

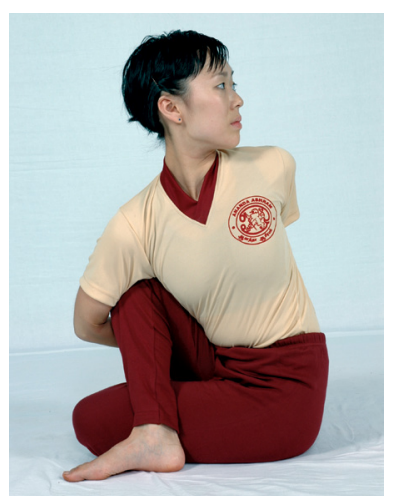


knee and catch hold of the right big toe. Your left shoulder blade rests on the outer side of your right knee.

Take your right hand round your back and try to get a grip on your left thigh. Look back over your right shoulder. The erect knee acts as a fulcrum for getting maximum twist of the spine. Keep your trunk vertical. Hold the posture for 30 seconds with soft breathing. When you are ready slowly release the posture and come back to the Uttana Asana.

\section{CHATUS PADA ASANA AND VYAGRAHA PRANAYAMA}

Take up the Chatus Pada Asana with your weight evenly distributed between your hands and knees. Start breathing in and out for an equal count of six. While breathing in slowly lift your head and arch your back downwards. Then breathe out slowly and lower your head while arching your back upwards. Breathe in while lifting your head and arch your back down.

Breathe out while lowering your head and arching your back up. Repeat this excellent practice at least nine times at each session. Vyagraha Pranayama helps us to utilize all sections of our lungs in a balanced and controlled manner thus energizing the whole body with healing Pranic energy.

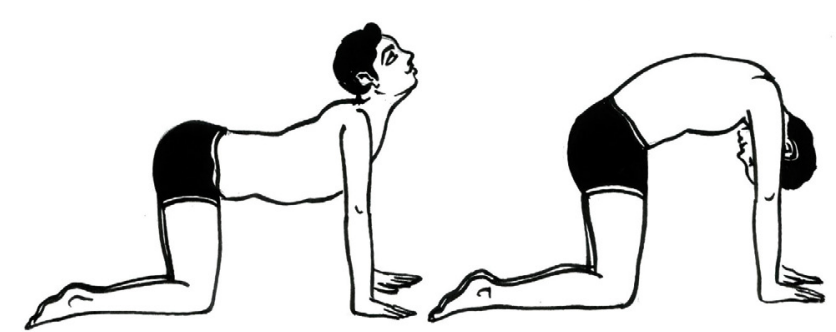

When ready slowly relax back to the Vajrasana for a period of quiet contemplation.

\section{BHUJANGINI MUDRA}

To perform the Cobra gesture, take up the Unmukha Asana which is a prone position with your entire body in a straight line.

In this technique the emphasis is on the breathing pattern and the production of a mighty hissing sound through the clenched teeth. Slowly bring your arms forward and keep your palms on the ground alongside your shoulders. Take in a deep breath. While making a mighty hissing sound, flare back into the Bhujanga Asana. Slowly relax back onto the floor while breathing in and then again flare back with a mighty hiss. Repeat this Mudra at least three to six times at each session. This technique helps release the pent up stress that accumulates in our system from our daily life and provides great emotional and mental relief.

It is an excellent stress-buster and is a must for all in this day and age. After completing the practice come back down to the face prone pose. Place your arms alongside your body and turn your head to the side. Relax for a few minutes and let the benefit of this Mudra seep into each and every cell of your body.

\section{PAWAN MUKTA ASANA}

Lie down in a comfortable Shavasana and start to breathe in and out for an equal count of six or eight. To perform the single legged Eka Pada Pawan Mukta Asana bend and lift your right knee while breathing in and simultaneously also lift your head off the ground. Catch hold of your knee with your arms and try to touch your knee to your forehead. Hold the position a few seconds and then while breathing out slowly release the position and lower your head while at the same time bringing your foot back to the ground.

Repeat this at least two more times to complete a set of three rounds of the practice. Relax a few seconds in the Shavasana and then perform the practice on the left side. Relax in Shavasana for a few minutes with deep and rhythmic breathing while concentrating on your abdominal area that will help to relax you further.

To perform the double legged Dwi Pada Pawan Mukta Asana bend and lift both your knees while breathing in. Bring them as close to your forehead as possible while simultaneously raising your head to meet the knees. Hold a few seconds and then while breathing out, lower your

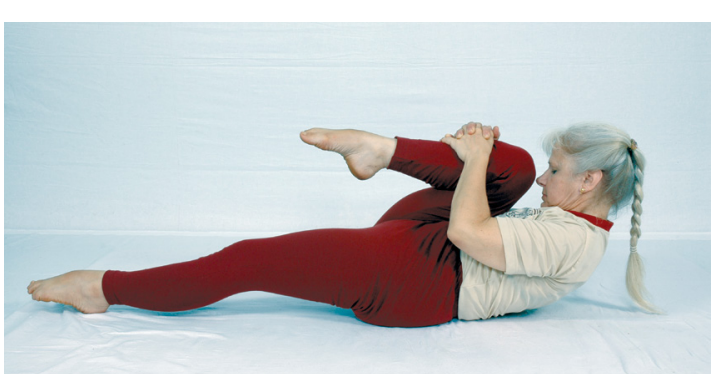


head and simultaneously bring your feet back to the ground. Repeat this two more times to complete a set of three rounds at each session.

Relax in Shavasana for a few minutes with deep and rhythmic breathing while concentrating on your abdominal area. This will help you to relax even further as the emotional tensions tend to tighten up the abdominal area leading to a feeling of "butterflies in the stomach".

\section{EKA PADA UTTANPADA ASANA}

From Shava Asana lift your right leg up towards the sky on the in breath. Try not to bend the knee if possible. On the out breath lower the leg back to the ground. Use a breath cycle of in and out for a count of six or eight.

Repeat this two more times. Perform the same practice on the left side. Lift your left leg up towards the sky on the in breath. Try not to bend the knee if possible. On the out breath lower the leg back to the ground. Use a breath cycle of in and out for a count of six or eight. Repeat this two more times. After performing the practice at least three times on each side relax in Shava Asana with deep breathing.

\section{DWI PADA UTTANPADA ASANA}

From Shava Asana lift both legs up towards the sky on the in breath. Try not to bend the knees if possible. On the out breath lower the legs back to the ground. Use a breath cycle of in and out for a count of six or eight. Repeat this two more times and then relax in Shava Asana with deep breathing. Those who have back problems should not do straight leg lifting and should do it with bent knees instead to avoid increasing the strain on the back.
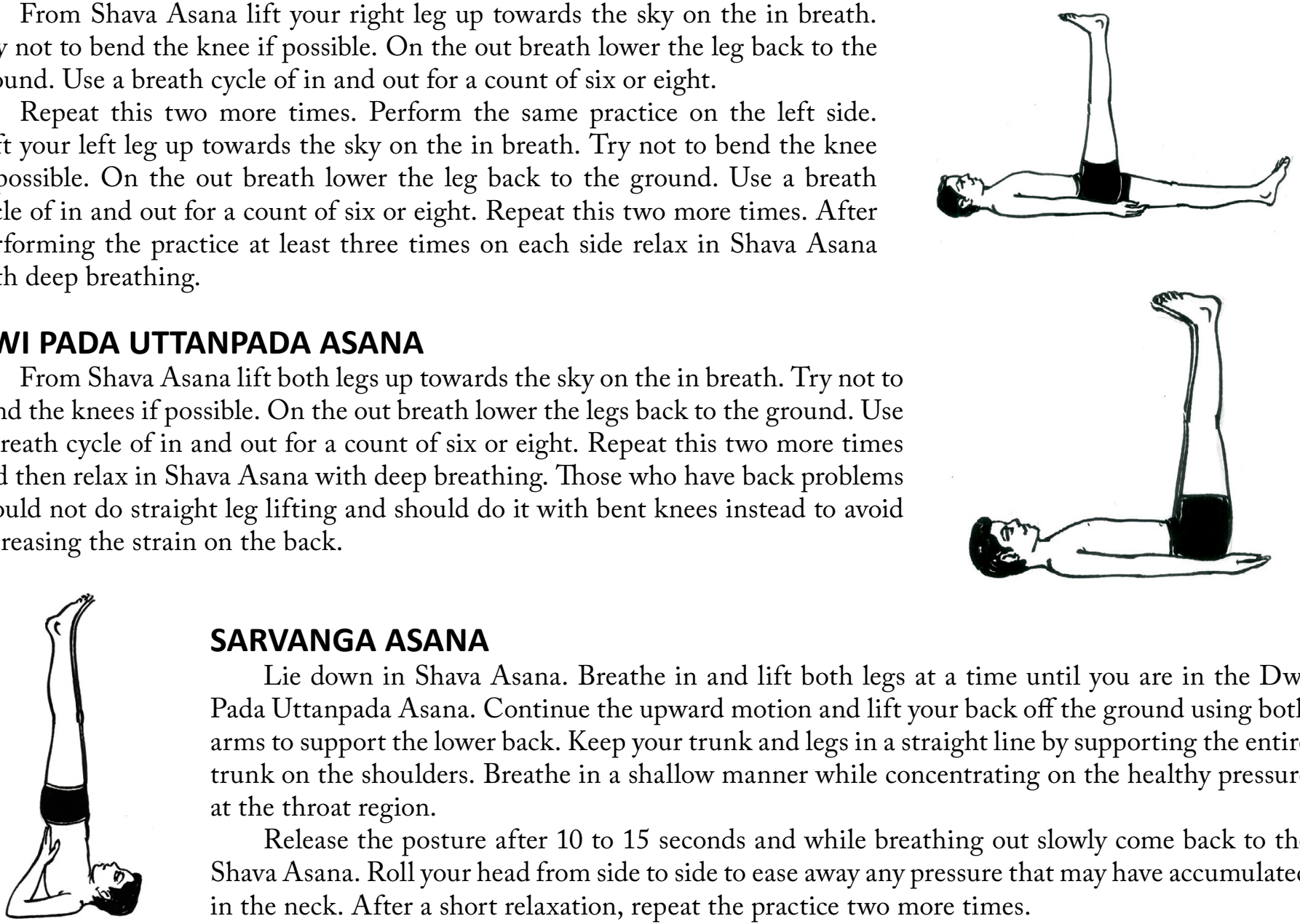

\section{SARVANGA ASANA}

Lie down in Shava Asana. Breathe in and lift both legs at a time until you are in the Dwi Pada Uttanpada Asana. Continue the upward motion and lift your back off the ground using both arms to support the lower back. Keep your trunk and legs in a straight line by supporting the entire trunk on the shoulders. Breathe in a shallow manner while concentrating on the healthy pressure at the throat region.

Release the posture after 10 to 15 seconds and while breathing out slowly come back to the Shava Asana. Roll your head from side to side to ease away any pressure that may have accumulated in the neck. After a short relaxation, repeat the practice two more times.

\section{VIPARITA KARANI}

Viparita Karani is the shoulder stand-like Mudra where the weight of the body is supported by the elbows while the hands are placed against the pelvic girdle. From the supine Shavasana slowly lift both your legs up as if performing the Sarvangasana. However the weight of your body should be balanced on your elbows and arms and not on your shoulders.

Hold the posture in a comfortable manner and then start to perform the incomplete and complete actions of this Mudra.

Perform the incomplete action by taking a deep inhalation and bringing your straightened legs towards your head so that your body makes an acute angle. Then perform the completed action by pushing your legs away while exhaling the breath. Make sure that your feet are extended in a rigid position making an obtuse angle.

Breathe in bringing your feet towards your head 1-2-3-4-5-6. Breathe out pushing your feet away 1, 2, 3,4,5,6.

Continue the practice for a minimum of three to nine rounds of this alternation between the incomplete and complete postures with the breath cycle at every session.

This Mudra promotes a healthy metabolic function by stimulating the pancreas and the uptake of insulin by cells of the body. It is highly recommended for the prevention, control and possible cure of conditions such as Diabetes Mellitus 
and imbalances of the thyroid gland. When ready slowly bring your legs down to the ground in a phased manner and enjoy a quiet period of relaxation in the Shavasana.

\section{SHAVASANA WITH SAVITRI PRANAYAMA}

Lie supine on the ground with your head preferably to the north enabling your body to be in alignment with the earth's electromagnetic field. Make sure that your head and body are in a straight line while hands are kept relaxed by side with palms facing upwards. Bring your feet together and let forefeet fall away into a ' $v$ ' shape with heels as close together as possible.

Start to consciously watch your breath by letting your awareness settle in the abdominal area. Feel the abdominal movements as your abdomen rises as you breathe in and falls as you breathe out. After a few rounds of this practice, slowly let your awareness settle at the tip of your nose. Feel the cool inspired air flowing into your nostrils as you breathe in and become aware of the warm expired air flowing out of the nostrils when you breathe out.

Consciously regulate your breath so that the duration of the incoming and outgoing breathes are equal. The inspiration and expiration can be for a count of 4 or 6 initially and then with practice elongated to a count of 8 or 10. Perform at least nine rounds of this conscious deep breathing and enjoy the relaxed sensation that spreads throughout your body.

Relaxation in Shavasana can be further deepened by utilizing Savitri Pranayama to relax and rejuvenate your body, emotions and mind. Breathe in through your nose for a count of 6 . Hold in the breath for a count of 3 . Breathe out through your nose for a count of 6 . Finally hold the breath out for a count of 3 . Make sure that you are breathing in and out through both nostrils and that you are using the complete Yogic breathing. Perform at least 9 rounds of this combination practice that heightens the relaxation to a very deep level.

After performing 10 to 15 minutes of the Shavasana slowly start to move your fingers and toes. Perform conscious stretching and make a smooth transition from the relaxed to the active state. Lift your left arm over your head and turn over onto your left side. Continue the turning action until you come into the face-prone posture. Perform Makara Asana by placing your right hand on the left while the left is placed palm down on the ground in front of you. Keep your forehead or chin on your right hand while keeping your legs a foot apart. Bring your hands forward near your shoulders and push yourself back into the Bhujanga Asana. Continue the back bending movement and go into the four footed Chatus Pada Asana. Relax into the Shashanga Asana with your arms stretched out in front and then finally come back to the Vajrasana. With your palms on your thighs sit quietly for some time and enjoy the effects of the deep relaxation that has spread to every part of your body.

\section{SPANDA - NISHPANDA KRIYA}

This practice is done from Shavasana using the yogic concept of Shpanda Nishpanda, which means the coupling of tension and relaxation. We consciously tense different parts of our body as much as possible and then relax them to the maximum in a step-by-step manner. This produces a better relaxation response than the mere attempt to relax without putting in the initial effort of tension.

Lie down in a comfortable supine Shavasana with your entire body in a singe straight line. After a few seconds of relaxation in this position, start to tense your entire body part-by-part from your toes up to the top of your head until every part of your body is as tense as possible. Hold this 100\% tension state of Spandha for a few seconds. Let all the muscles of your entire body be as tense as possible. At the peak of the tension, just 'let go' and immediately relax your entire body $100 \%$. This is the state of Nishpanda. Enjoy this relaxed state and with conscious awareness continue to watch your breath as it comes in and goes out of your nose.

Repeat this practice again by tensing up your entire musculoskeletal system to the state of Spandha and hold it for a few seconds. When ready let go completely and enjoy the Nishpanda state for a few minutes.

To complete the practice repeat the Spandha - Nishpanda Kriya a third time by tensing up your entire musculoskeletal system from your toes to the top of your head. Hold the complete tension for a few seconds. When ready let go completely and enjoy the complete relaxation that ensures. Be aware of how all your muscles relax in this practice because the relaxation is deepened when it is contrasted with tension.

This practice is a boon for those suffering psychosomatic, stress induced and stress aggravated life disorders such as hypertension, diabetes, asthma, insomnia, peptic ulcers and bowel disorders. 


\section{MARMANASTHANAM KRIYA}

The twenty-two sensitive parts of the body are known by the collective Sanskrit term Marmanasthanam. To concentrate upon these parts in a particular order or to command these areas to relax in a particular way while concentrating, gives a very satisfactory, deep relaxation that has been found by tested experiments to give relief even to compulsive dreaming. This is an excellent Kriya to do at the end of a strenuous session of Asanas and Pranayamas. The relaxation should be preceded by at least nine rounds of Savitri Pranayama, the Rhythmic Breath, to create the proper atmosphere. This technique (Kriya) can be done in two ways, one for relaxation the other for deep concentration. For relaxation the technique is done from "feet to the head." For deep concentration from "head to feet." While concentrating upon twenty-two body parts, each part is commanded (by mind) "to relax" or a thought of peace or serenity" directed to the areas.

For relaxation, concentrate upon the (1) toes and command the toes to relax (2) feet (3) lower legs to knees (4) upper legs to hips (5) buttocks (6) base of spine (7) pelvic area (8) abdomen (9) chest and (10) shoulders. Now take your concentration down to the (11) fingers, and command the fingers to relax then (12) hands (13) lower arms to elbows (14) upper arms to shoulders where your concentration joins with body concentration (15) throat (neck) (16) around the mouth and chin (17) around the nose and cheeks (18) eyes (19) back around the ears (20) back of the head (21) top of the head (22) Cavernous Plexus in the middle of the forehead. All the while you should command "relaxation." Perform Jyoti Dharana and Jyoti Dhyana (concentration and meditation on the Divine light) at the Bhrumadhya Bindu (Midpoint between the eyebrows). Visualize the Divine Jyoti to be having the brilliance equal to 1000 suns but without the glare. Absorb yourself into this Divine Jyoti.

\section{PRANAYAMA PRACTICES}

\section{PRANAVA PRANAYAMA}

'Tasya vachakah pranavaha', the sacred sound of the Divine is the Pranava says Maharishi Patanjali. This develops abdominal, thoracic and clavicular regions of the lungs to their maximum capacity. This Pranayama has unlimited healing potential and brings about harmony of body, emotions and mind. It is an important part of Rishiculture Ashtanga Yoga tradition as taught by Yogamaharishi Dr Swami Gitananda Giri Guru Maharaj.

Adham Pranayama, the abdominal or lower chest breathing. Put the fingers into the Chin Mudra with the index and thumb fingers touching each other at the tips. Keep the
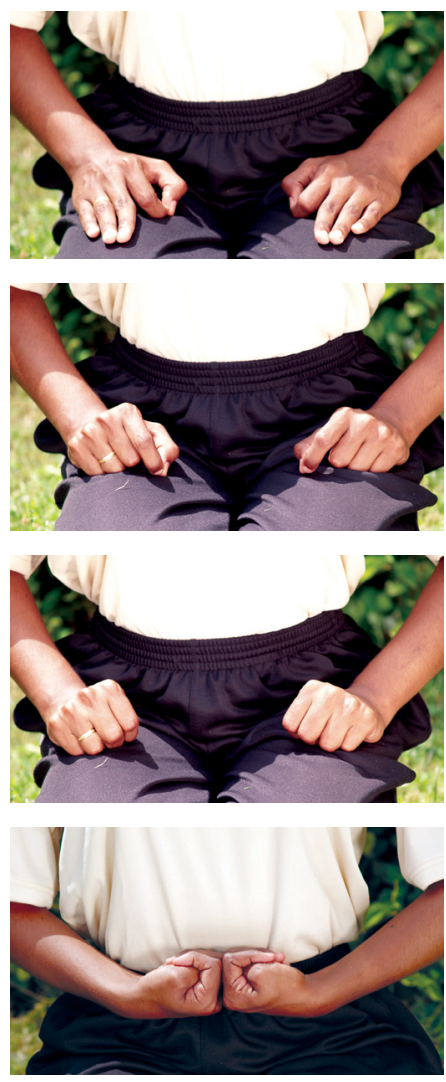
other three fingers straight and united. Take a deep breath into the lower chest and abdominal regions and then let it out with the sound aaa.......

To perform thoracic or mid-chest breathing, the Madhyam Pranayama, curl your fingers inward to form Chinmaya Mudra. Take a deep breath into the mid chest and thoracic regions and then breathe out with the sound ooo.......

Adyam Pranayama is the clavicular or upper chest breathing and utilises Adhi Mudra. Clench your fists with your thumb in the centre. Keep the Adhi Mudra on your thighs and breathe deeply into the upper chest and clavicular regions and then exhale with the sound $\mathrm{mmm} . . . . .$.

Joining the earlier three parts of the breath in a complete Yogic breath is the fourth stage, known was Mahat Yoga Pranayama. Put the Adhi Mudra with knuckles of your right and left hands touching in front of the navel. This is now known as the Brahma Mudra. Take a deep breath into the low, mid and upper chest regions. Now let the breath out with the sounds of aaa...ooo...mmm.... Relax and enjoy the feeling of potent healing energy flow through the entire body.

\section{NASARGA MUKHA BHASTRIKA}

Nasarga Mukha Bhastrika is a forceful expulsion of the breath through the mouth that can accompany different movements to relieve our pent up stress.

Take up a comfortable standing position and then start to shake your hands as vigorously as possible to help loosen up the accumulated tensions of your daily life. Visualize all the tensions that have accumulated in your wrist and elbow joints getting a good 'shake up' by this action. When you have got the tensions loosened up, take in a deep breath through your nose and clench your fist as if catching hold of all your tensions and stress. Now with a powerful blast through your 
mouth "whoosh" away all your accumulated tensions and stress as forcibly as possible.

Again shake your hands as fast as possible. Breathe in and catch hold of the tension in your fist. Throw it all away with a blast. Make sure that you are using your diaphragm muscle vigorously while blasting out the breath in this practice.

Perform this practice 3, 6 or 9 times as necessary. After performing 3 to 9 rounds of this practice, relax in the standing position and enjoy the feeling of relief that sweeps through your arms as you relax with some deep breathing.

\section{CHANDRA PRANAYAMA}

Sit in Vajrasana and perform Nasarga Mudra with your right hand. Close your right nostril with your thumb. Inhale slowly through your left nostril for a count of four. Now exhale through the same left nostril for a count of eight.

Keep your right nostril closed throughout the duration of the practice. Repeat the Chandra Pranayama for a minimum of nine rounds at each session.

Patients of lifestyle disorders such as anxiety, hypertension, insomnia, diabetes and other stressful conditions can benefit by practising this Pranayama 27 times before breakfast, lunch, dinner and before going to bed at night.

\section{BHRAMARI PRANAYAMA}

Sit on the heels in the Vajrasana with the spine erect. Perform the Shanmuki Mudra with the thumbs of the hands closing the external auditory canal. The first two fingers are then placed over the closed eyelids while the ring fingers regulate the flow of air through the nostrils. The little fingers are placed over the closed lips. This Mudra helps in joining together the nerves of the hands with the facial and trigeminal nerves on the face.

Take a slow and deep breath in for six counts. Let out the breath very slowly while making a sound in the nasal passages like the high-pitched sound of a female bee. This buzzing sound is very much like the Anuswarah sound of "mmm" of the Pranava AUM. Repeat this at least nine times.

Bhramari is one of the Swara Pranayamas and stimulates the secretions and tones up nerve centres. This helps relive Pitta conditions and rejuvenates the skin. It also creates a beautiful voice. It is a contemplative prelude to Nada Yoga.

\section{CONTEMPLATIVE PRACTICES}

PRANA DHARANA -BREATH AWARENESS: Sit in Vajrasana or lie down in Shava Asana. Begin to be aware of your breathing and how the air passes down from the nostrils into the lungs and then back out the nostrils. Feel the abdominal movements as the abdomen rises with the in breath and falls with the out breath. Let your awareness settle in the abdomen. Feel the cool inspired air flowing into the nostrils and the warm expired air flowing out of the nostrils. Let your awareness settle at the tip of the nose. Consciously regulate the breath so that the ratio of insp: exp is equal. It can be a 4,6,8 or 10 count. Perform nine rounds of this practice.

MINDFULNESS BASED MEDITATION: One of the most productive of the many forms of "quiet sitting", popularly grouped under the heading of meditation is the mindfulness based awareness of one's thoughts. This is to be done without identifying with the thoughts and without either justifying or condemning them. Take up a straight back sitting position and sit facing to the North or East in the early morning. Keep your mind as placid as possible, as this is the important feature of the early morning meditation. Breathe slowly and rhythmically, but very quietly. Do not upset the peace. Hold your mind concentrated inside your head at a point in line with the eyebrows. Relax. Don't attempt to force visualization, simply be alert and expectant. Presently, you will have the sensation of movement within the head, as though watching a "ticker tape" of your thoughts. The thoughts will be in extreme slow motion. Observe the thoughts. Don't get emotionally involved with them, just watch them. You will actually be able to see your thoughts, as well as hear them. Usually, the thoughts are quite mundane, but benign. Simply observe them, passively and dispassionately.

OM JAPA: Take up any meditative posture and start to perform the Savitri Pranayama in a 6 by 3 or 8 by 4 rhythm. Make an audible Pranava OM in the Bindu Nadi. With Japa-Ajapa, make silent intonation of the Pranava OM concentrating at this same point. Do not let the mind waver away from either a conscious repetition of the Mantra OM, as Japa, or as the silent Ajapa.

AJAPA JAPA: Take up any meditative posture and start to perform the Savitri Pranayama in a 6 by 3 or 8 by 4 rhythm. As you breathe in listen to the sound of SAH made as the breath enters your respiratory passages. As you breathe out listen to the sound of HUM that is made as the breath leaves your respiratory passages. Concentrate on this Ajapa Japa of HAMSA SOHAM in tune with the breath. 